\title{
Commentary: "Beyond Pathologizing Harm: Understanding Post-Traumatic Stress Disorder in the Context of War Experience."
}

\author{
Deborah R. Gordon 1*, Patricia Benner ${ }^{1}$, Jodi Halpern' ${ }^{2}$, Catherine Long Popell ${ }^{3}$, and Patricia W. Kelley \\ 'University of California, San Francisco, CA, USA \\ ${ }^{2}$ University of California, Berkeley, CA, USA \\ ${ }^{3}$ Services for Brain Injury, San Jose, CA, USA \\ ${ }^{4}$ Duquesne University, Pittsburgh, PA, USA
}

Article Info

\section{Article Notes}

Received: February 06, 2018

Accepted: April 19, 2018

\section{*Correspondence:}

Dr. Deborah R. Gordon, University of California, San

Francisco, 3333 California St., suite 485, San Francisco,

CA, 94143, USA;

E-mail address: Deborah.Gordon@ucsf.edu

C 2018 Gordon DR. This article is distributed under the terms of the Creative Commons Attribution 4.0 International License.

\section{Keywords:}

Post-traumatic stress disorder or PTSD

Combat trauma

Experience of war

Phenomenology

Nursing care

Wounded servicemen

\section{Original Article Citation:}

Benner P, Halpern J, Gordon DR, Popell CL, Kelley PW.

Beyond Pathologizing Harm: Understanding PTSD in the

Context of War Experience. J Med Humanit 2018; 39: 45-72

Doi: https://doi.org/10.1007/s10912-017-9484-y.

\section{Abstract}

Hermeneutic phenomenology provides an alternative to objectifying approaches to understanding Post-Traumatic Stress Disorder (PTSD). PTSD is the one major psychiatric diagnosis where social causation is established, yet PTSD is predominantly viewed in terms of the usual neuro-physiological causal models, with traumatic social events viewed as pathogens with dose-related effects. However, framing PTSD as an objective disease state separates it from the narrative historical details of the trauma. Personal stories and cultural meanings of the traumatic events are seen as epiphenomenal, unrelated to the understanding of, and ultimately, the therapeutic treatment of PTSD. Sixtyseven US service members injured in the Iraq and Afghanistan wars who were in the rehabilitation phase of their recovery, and 401 nurses who provided care for service members, were interviewed. Most wounded service members described classic symptoms of PTSD: flashbacks, insomnia, hyperarousal, etc. All experienced disturbance in their sense of place and time: distortions and ruptures between "here" and "there," "then" and "now." Effective nursing care required being attuned to where a patient is "at" phenomenologically. Rather than see the occurrence of these symptoms as decontextualized mechanistic reverberations of war, we consider how these symptoms meaningfully reflect actual war experiences and the sense of displacement experienced by service members.

\section{Introduction: An Objective Approach to Post-Traumatic Stress Disorder}

Often described as a signature diagnosis of service members injured in the Iraq and Afghanistan wars ${ }^{1}$, Post-Traumatic Stress Disorder (PTSD) is the one major psychiatric diagnosis where social causation is officially recognized. Yet PTSD has come to be understood predominantly in terms of neuro-physiological causal models, with traumatic social events viewed as pathogens with doserelated effects ${ }^{2}$. Regarded as an objective, verifiable, discrete, and preventable disorder ${ }^{3,4}$, a PTSD diagnosis is based on a standardized set of types of symptoms, such as: intrusive memories, nightmares, flashbacks, intense distress after exposure to trauma-related stimuli, and avoidance of reminders, which are directly related to a specific traumatic event-the "stressors."

As an objective disease state, the truth about PTSD is considered to be independent of narrative historical details of 
the trauma. Colonel C. Castro, director of the Military Operational Medicine Research Program, questions this undifferentiated approach to PTSD trauma in the most recent DSM 5 definitions of $\mathrm{PTSD}^{6}$ :

“...the words 'combat,' 'veteran,' or 'military' do not appear anywhere in the diagnostic description, not even in the section devoted to high risk occupations. The scientific evidence for lumping combat-related PTSD with PTSD related to other forms of trauma, such as sexual or physical assaults, and survivors of natural disasters is questionable... ${ }^{\prime \prime}$

Personal stories and cultural meanings of the traumatic events are also seen as epiphenomenal, unrelated to the understanding and ultimately the treatment of $\mathrm{PTSD}^{7,8}$. Rather, much treatment is geared toward eliminating symptoms, such as "straightening out" the pathological temporality of memory causing the re-experiencing of the traumatic event and correcting pathologized modes of perception and behavior, such as avoiding or overreacting to stimuli associated with the traumatic event ${ }^{9}$. The longterm goal is to help wounded service members (WSMs) separate their military and civilian selves ${ }^{10}$ and return to normalcy to the degree possible.

This model of PTSD has contributed much to garnering attention to the need to address and treat combat-related symptoms, and there is value in having symptom checklists for PTSD and assessments based upon general, observable signs and symptoms, such as MRI neuro-imaging evidence of typical brain changes. However, without additional firsthand "experience-near" accounts of actual events ${ }^{11}$, the meaning and context of the trauma are left out; this can be misleading, even harmful, and limit the efficacy of treatment and delay recovery. Objectification, i.e., conceptually removing the person from his/her context, precludes understanding the person's perceptions and behavior as meaningful and reasonable activity in a particular, not a generic, context. Understanding WSMs' contact with reality, the meanings and concerns they actually experienced (e.g., watching the death of a "buddy") ${ }^{12,13,14}$ can avoid pathologizing experience. Given the stigma associated with mental illness and PTSD, this matters ${ }^{3}$. Such understanding can also provide a fundamental basis for providing effective and therapeutic care.

\section{A phenomenological approach to PTSD}

Our article, "Beyond Pathologizing Harm: Understanding Post-Traumatic Stress Disorder (PTSD) in the Context of War Experience," offers an alternative understanding of PTSD that is grounded in hermeneutic, or interpretive, phenomenology. This phenomenological perspective $\mathrm{e}^{15,16,17}$ builds on the assumption that to be human is to be embodied and immersed in the emotionally meaningful, palpable environment one inhabits. Personal and cultural history directly shape embodiment through learning and acquiring specific skillful ways of being in the world, which we refer to as body habitus ${ }^{18,19,20,21}$. The military, in fact, is known for instilling a distinct military habitus, including one that fosters combat readiness ${ }^{22,1}$.

In particular combat and war zones, for example, service members learn to perceive new sources of danger and new levels of attentiveness and skills to respond to danger; they learn how to live and survive in a constant surround of threat, and how to participate in intense emotional life-anddeath relationships of trust and loyalty ${ }^{8,23}$. These totalizing challenges of combat radically alter and create new ways of being in the world; they can change the very "world" a WSM lives $\mathrm{in}^{4}$. Many of these changes become part of who the person is. Every service member leaves war with some shifts in embodied memory, identity, and sense of meaning that color understanding of his or her current and future lifeworld. From a situated phenomenological perspective, experience in the war zone is formative.

Our method of study has been to adhere closely to the first-hand interview accounts of sixty-seven US wounded service members injured in the Iraq and Afghanistan wars and of 401 nurses who provided care for WSMs in a broad range of locations. Most of these WSMs described classic symptoms of PTSD, e.g., flashbacks, insomnia, a startle response to reminders, etc.; all experienced disturbance in their sense of time and place. Rather than see these symptoms as decontextualized mechanistic reverberations of war on the brain and body, we consider how they meaningfully reflect service members' actual war experiences with real traumatic events and subsequent sense of displacement, as described by the WSMs and nurses in this study ${ }^{12}$.

The relevance of an interpretive phenomenological approach for understanding post-war experience and symptoms of PTSD

Taking an interpretive phenomenological rather than a diagnostic approach to interpreting our research participants' accounts, we inductively identified a recurring set of experiences and themes. Many offer another way of describing and understanding PTSD symptomatology of a returnee without pathologizing their responses.

Distortions, ruptures, and altered senses of time and place were ubiquitous, reflected in important distinctions between "then" and "now" and "here" and "there", as if they referred to two different experiential worlds. This is well captured in one WSM's account that we describe as "being there, not here":

"I came recently from war. I could be here, but ... I'm still over there [in Afghanistan]... I don't know if you understand. And even with my condition [severely 
injured], I'm still in defense mode. I'm always defensive. I can't find a way... [to] lower that defense mode. I can't, even if I go somewhere where there are a lot of people like a Mall, I can't. I have to leave."

This soldier was especially aware and articulate about his shifts between immediate past war experience and the present, an awareness that many do not initially have, inhabiting all simultaneously ${ }^{4}$. Still "over there," his embodied habitus remains in the defensive mode that he needed in the war context.

In fact, the fluidity and variability in where a person is "at" experientially, not geographically, was a theme with some of the following variations:

- Not being able to be "here": Acute grief, general anxiety, inability to focus in the moment;

- Embodied responses to environmental cues "here" as if they were "there," in the war zone;

- Flashbacks and nightmares: the intrusive return of being "there."

- Imagining the comforts of home while being "there";

- Being "here" while longing to be back "there" in the war zone; and

- Stigma, social isolation and detachment "here" after being connected "there."

The experience of war radically reshapes a service members' embodied sense of threat, skills, and identity. Many of the phenomenon considered to be symptoms of PTSD, such as flashbacks, nightmares, fear and avoidance, can be understood as learned responses in the context of war that can show up as symptoms when "home," in what now uncannily feels like a more dangerous world. The coping necessary in their postwar lifeworlds can be diametrically opposed to many of the embodied practices that helped with survival during war: hypervigilance that is no longer warranted shows up as acute anxiety, paranoia or hostility; appropriate caution in daily social interactions with civilians in a war zone can appear as aloofness back at home.

Understanding how formative war experiences are embodied in perceptions and body memories that cannot be shed like a military uniform helps us better understand how the experiences associated with PTSD can be logical and not necessarily pathological responses to experience in war of all returning soldiers, whether or not they become officially diagnosed with PTSD $^{9,23}$.

The implications of an interpretive phenomenological approach for immediate and long-term care, recovery and healing of combat-related trauma

Applying a phenomenological-contextualist approach to trauma ${ }^{23}$, psychoanalyst Robert Stolorow understands trauma as "unbearable affect," not the specific event itself; its effects include a shattering of one's experiential world and an excruciating sense of singularity, solitude, and shame, among others ${ }^{24,25}$. Understanding affects as relational, these difficult emotions must be processed with other people in order to integrate them. This requires "attunement" from those who observe and listen to the WSM's war experiences, such that WSMs "feel understood," "feel gotten ${ }^{24,25 . "}$

Yet not feeling heard or understood was the experience many WSMs expressed, often founded on the conviction that only people who had "been there" and "done that" could really understand or help them. It was this common conviction that psychoanalyst Judith Broder, the founder of The Soldier's Project, worked to overcome. In fact, the project has shown how working with volunteer civilian therapists -- who have skills to listen empathically even though they have not actually been there ${ }^{26}$-- has helped WSMs find a path to trusting family members and civilians.

Perhaps the most frequent descriptor of experience used by both WSMs and nurses was "shattered," referring to bodies and limbs shattered by the Improvised Explosive Device (IED) blasts, but also to the shattering of a lifeworld, of a close-knit unit of "buddies," of a person's life and life story, of an aspired future, of the world as one knew it. WSMs expended great effort to learn the details of their injury, to make sense of it, and to try to put their story back together again in some way.

Nurses played an important role in collecting and holding the WSMs' stories $^{27}$, and many of the positive and negative stories about nursing care involved attunement or lack of it. Given the service members' profound fluctuations in lived time and space, nurses needed to understand where a person is "at" in time and place. In fact, we heard sensitive and creative ways by which nurses successfully "met" the WSM where he was at: by developing a protocol for carefully waking up a newly arrived patient, for example, or by reducing stimuli in the room that could be interpreted as dangerous to someone still living "in the field." We heard how a nurse helped bring a confused marine back from a flashback to himself in the present by playing the "Marine Hymn" for him on an IPhone and holding his hand while listening together; another nurse offered a patient with a shaved head her knitted cap for warmth; the patient was caught up by the smell of shampoo of the cap, a smell that appeared to recall the comforts of home, femininity and warmth that was so good, he passed the cap around to his comrades to smell.

\section{Discussion: Beyond War-Related Trauma}

The exclusive focus on war-related PTSD of this paper raises a number of important questions: how relevant 
are these findings and analysis to other sources of PTSD, such as sexual or physical assault, ongoing civil war, or natural disasters? Are we proposing that PTSD caused by war-related trauma is a different diagnosis than PTSD caused by other sources of trauma? Does this interpretive phenomenological approach also apply to other sources of trauma? And how to understand distortions of time and place found among most patients with PTSD, not only warrelated PTSD?; can we understand such shared symptoms as natural human reactions without supposing biological pathology? Here we briefly address each of these questions.

Is war-related PTSD a different diagnosis? While we presented our hermeneutic phenomenological approach to PTSD through the specific example of war-related PTSD, we do not necessarily hold that this is a different diagnosis than other PTSD diagnoses. We do mean to demonstrate the fundamental variability within a PTSD diagnosis and that PTSD is not an objective, singular, unitary disorder ${ }^{4}$, independent of the particular historical and narrative details of the experience of trauma. This is not a novel argument in the field. Based on years of research in military mental health, Drs. Amy Adler and Carl Castro identified important differences in the reactions, symptoms and functional impairment between two models of a traumatic event: the "traditional, "victim" event model, such as from sexual assault or weather disaster, that is unexpected and unwanted, and the military combat-related or "occupational" event model that is generally expected, prepared for and repeated, and in which service members are not usually passive victims but often also aggressors, sometimes even desiring to return to the front for more ${ }^{\mathbf{2 8 , 6}}$.

By pointing to the importance of the context of a traumatic event, these typologies challenge a generic approach to PTSD. In this paper, we argue for even more specificity of context: that the experience of trauma is constituted at a particular intersection of history, personal stories, cultural meanings, and social and material conditions. While there are commonalities across contexts and people, it is the particular historical experience that matters to the person and that is the basis of a traumatic experience. Thus, we argue that all those diagnosed with PTSD, whatever the source, should have their lived, historical traumatic experiences taken into consideration when assessing "natural" vs. "pathological" reactions, when determining a diagnosis, and when deciding on and enacting treatment. This leads to a second related question.

Can a hermeneutic phenomenological approach be applied to other types of trauma? This necessity of understanding the specific content and nature of a traumatic experience entails the relevance and value of taking an interpretive phenomenological approach to noncombat-related PTSD, including those involving single incident traumas. We strongly regard this approach as an essential alternative to the current objective, psychopathological, neuro-physiological and cognitive approaches that dominate the field, and for the following reasons.

First, an interpretive phenomenological approach focuses on situated lived experience. Understanding the real-world experiences of individuals diagnosed with PTSD is fundamental for their own self-understanding as well as for understanding what they have in common with others with related trauma but without an official PTSD diagnosis $^{8,23}$. This understanding also enables people to share these experiences not only with others who have "been there," but with those who haven't but who are important in their lives, such as family members. This can provide the basis for creating a relational bridge to cut through the isolation, shame and distance and help absorb the indigestible affect that is at the basis of trauma ${ }^{24,25}$.

Second, an interpretive phenomenological approach highlights the formative, embodied nature of traumatic experience. In contrast to common expectations, one rarely returns to being the same person one was pre-trauma. Rather, traumatic experience can radically transform what it's like for the person to be in the world, what matters to him/her, what is noticed, sensed, feared and so on. Reactions or symptoms are not merely superficial and temporary leftovers, such as cognitive misperceptions, inappropriate fears, or excessive negativity. They also constitute embodied change in who one is, in one's ways of being in the world, in one's world.

Third, a contextual, historical approach such as interpretive phenomenology is interpersonal rather than overly individualist. It recognizes the co-constituting relationship between individual biography and social and historical context in shaping experience and embodiment, even determining what is or is not traumatic in the first place. Like the experience of being in combat, the effects of other traumas can be more extensive than the symptoms that are officially recognized as PTSD.

How, then, to understand similar disturbances in time and place among all PTSD patients? Situated phenomenological accounts of human experience describe commonalities in how people ground themselves in reality by experiencing themselves temporally as "now" versus "then" and spatially as "here" versus "there," according to the psychological salience of events. For example, Merleau-Ponty's phenomenological theory of "breadth psychology"29 -- in which a past event extends into the present where it gets "stuck" and spreads out into the foreground of a person's perception -- would predict that significant trauma would cause spatial and temporal slippage between here and there, then and now.

Further, phenomenologically, trauma is known to lead to experiences of dissociation; this contributes to a disrupted 
sense of time and place -- often of fusion or disjuncture -that translate into confusion or new experiences of space and time.

Finally, do the commonalities among people experiencing trauma from different sources implicate pathological biology? As noted, common, natural reactions to a potentially traumatic situation are not necessarily indicators of character or personal pathology. In fact, as many of us have argued ${ }^{3,4,8,23}$, typical PTSD symptoms, such as inappropriate fears that result from single or multiple encounters with extreme violence or disaster, may be normal, logical reactions to harm and suffering. They may of course also indicate biological dysregulation.

Biological and social processes are in dialogue; social experiences, particularly traumatic ones, leave traces of changes in the brain and on brain functioning. However, understanding biological pathology as a result of social trauma such as war, sexual abuse, violence, natural disasters and so on, is not the same as assuming biological pathology as the source or the cause of symptoms or physical changes in the brain. As PTSD is the one important psychiatric diagnosis that recognizes social causation, any analysis of causation must begin with the social dimension, which includes the meaning and lived history of an event itself. Brain pathology does not occur without an experience of trauma at the social level; PTSD symptoms cannot be reduced to, nor exclusively explained by, these traces of experience in the brain.

Thus, while useful, reducing trauma to a biological analysis or suggesting that in an "integration" of social with biological analysis, the biological carries more weight, is insufficient for effectively understanding, treating and preventing PTSD. Brain imaging and manipulation of brain chemistry may augment therapies targeted at the social meanings of the trauma for the person. However, they cannot replace the value of attention and therapies that seriously engage the meanings, the affect, and the historical social content of the trauma and that offer understanding of the lived experience of being immersed in a particular situation $^{4,7,8,23}$, however much the experiences correlate with brain changes. Such understanding is essential not only for decreasing the alienation and isolation a traumatic emotional experience typically causes and for reestablishing relationships, but also for societal prevention of future traumas.

\section{Conclusion}

Since people are both physical and narrative beings suspended in a lived history, we need both biological and phenomenological understanding. Yet PTSD is increasingly absorbed into the dominant, objective neuro-biological paradigm, a paradigm that erases context, meaning and experience as epi-phenomenal. More than a biological approach is needed. We call for a broader explanatory model for understanding and treating PTSD, one that shows how social and cultural meanings, or context, are constitutive of embodied experience, and one in which personal stories and specific narrative details, far from being epi-phenomenal, offer understanding that is essential for attuned care, relational treatment, and selfunderstanding.

Broadening our understanding of combat-related PTSD to include formative world and temporalityaltering outcomes for living after war will help normalize symptoms and increase understanding of the personal and social impacts of war. In place of the frequent question of whether or not a traumatized person has PTSD in absolute diagnostic terms based on objective evidence of pathology, the focus must be on coming to terms with WSMs' real war experiences and subsequent changes in their ways of being in the world after war.

Words 3228

\section{Acknowledgement}

Acknowledgement to M. Epstein, The Trauma of Everyday Life. New York: The Penguin Press; 2013. Special thanks and tribute to all Service members who participated in the study.

\section{Funding}

This study was funded by the TriService Nursing Research Program (TSNRP \# N08-P11), Uniformed Services University of the Health Sciences; however, the information or content of this Commentary and the conclusions of the Journal of Medical Humanities article do not necessarily represent the official position or policy of, nor should any official endorsement be inferred by, the TriService Nursing Research Program, Uniformed Services University of the Health Sciences, the Department of Defense, or the U.S. Government.

\section{Conflict of Interest}

Author Patricia Benner has no conflict of interest; Author Jodi Halpern has no conflict of interest; Author Deborah R. Gordon has no conflict of interest; Author Catherine Long Popell has no conflict of interest; Author Patricia Kelley has received research grants from TriService Nursing Research Program and has no conflict of interest.

\section{Ethical Approval}

All procedures performed in studies involving human participants were in accordance with the ethical standards of the institutional and/or national research committee and with the 1964 Helsinki declaration and its later amendments or comparable ethical standards. Human Subjects Research Approval was received by all 
participating institutions. Informed Consent was obtained from all individual participants included in the study.

\section{References}

1. Institute of Medicine. Treatment for Posttraumatic Stress Disorder in Military and Veteran Populations: Final Assessment. Washington, DC: The National Academies Press. 2014. https://doi. org/10.17226/18724

2. Hammer PS, Navy Capt. "DCoE Director Explains Science Behind PTSD." Defense Centers of Excellence for Psychological Health \& Traumatic Brain Injury. BrainLine. 2013; May 29.

3. Young A. The Harmony of Illusions: The Invention of Post-Traumatic Stress Disorder. Princeton: Princeton University Press; 1997.

4. Wool ZH. After War: The Weight of Life at Walter Reed. Durham, N.C. Duke University Press; 2015.

5. American Psychiatric Association. Diagnostic and Statistical Manual of Mental Disorders, 5th Edition (DSM-5). Washington, DC: American Psychiatric Association; 2013; http://dsm.psychiatryonline.org/ book. aspx?bookid=556

6. Castro CA. The U.S. framework for understanding, preventing, and caring for the mental health needs of service members who served in combat in Afghanistan and Iraq: a brief review of the issues and the research. EJPT. 2014; 5: 1, DOI: 10.3402/ejpt.v5.24713.

7. Hautzinger S, Scanlynd J. Beyond Post-Traumatic Stress: Homefron Struggles with the Wars on Terror. 1st Edition. New York: Routledge; 2014.

8. Finely EP. Fields of Combat: Understanding PTSD among Veterans of Iraq and Afghanistan. Ithaca: Cornell University Press; 2011.

9. Wool ZH. On Movement: The Matter of Soldiers Being after Combat Ethnos. 2012; 4-5.https://doi.org/10.1080 /00141844.2012.658428.

10. Molendijk T, Kramer EH, Verweij D. Conflicting Notions on Violence and PTSD in the Military: Institutional and Personal Narratives of Combat-Related Illness. CMP. 2016; 40 (3): 338-60. https://doi. or00g/10.1007/s11013-015-9469-0.

11. Geertz C. Interpretation of Cultures. New York: Basic Books; 1977.

12. See argument for retrieving realism through first person contact with reality.

13. Dreyfus HL, Taylor C. Retrieving Realism. Cambridge, Mass.: Harvard University Press; 2015.

14. Taylor C. The Concept of a Person. In Human Agency and Language: Philosophical Papers, Vol. I, 97- 114. Cambridge: Cambridge University Press; 1985.

15. Taylor C. Theories of Meaning. In Human Agency and. Language:
Philosophical Papers, Vol. I, 248-292. Cambridge: Cambridge University Press; 1985.

16. Merleau-Ponty M. The Phenomenology of Perception. Translated by D A Landes. New York: Routledge; [1962] 2012.

17. Benner P, Wrubel J. The Primacy of Caring: Stress and Coping in Health and Illness. Menlo Park, CA.: Addison-Wesley;1989.

18. Dreyfus H.L. Being in the World: A Commentary on Heidegger's "Being in Time, Div. I" Cambridge: M.I.T. University Press; 1991.

19. Bourdieu, P. Outline of a Theory of Practice. Cambridge: Cambridge University Press; 1977.

20. Bourdieu P. The Logic of Practice. Translated by R. Nice. Stanford: Stanford University Press; 1990.

21. Dreyfus HL, Wrathall MA. Skillful Coping: Essays on the Phenomenology of Everyday Perception and Action. Oxford, UK: Oxford University Press; 2016.

22. Dreyfus HL. Background Practices: Essays on the Understanding of Being. Edited by MA Wrathall. Oxford, UK: Oxford University Press; 2017.

23. Messinger SD. Vigilance and Attention Among U.S. Service Members and Veterans After Combat. Anthro of Consciousness. 2013; 24: 2, 191-207.

24. Stolorow RD. Trauma and Human Existence. New York: Analytic Press, Taylor and Francis Group; 2007.

25. Carr RB. Combat and Human Existence: Toward an Intersubjective Approach to Combat-Related PTSD. Psychoanal Psychol. 2011; 28:4, 471- 496.

26. Broder J. The Soldiers Project: Healing the Hidden Wounds of War. https://www.thesoldiersproject.org/about/ Accessed February 5, 2018.

27. Kelly PW, Kenny DJ, Gordon DR, Benner P. The Evolution of Case Management for Service Members Injured in Iraq and Afghanistan. Qualitative Health Research. 2015;25;3: 426-439. Article first published online: October 6, 2014; https://doi. org/10.1177/1049732314553228

28. Adler AB, Castro CA. An Occupational Mental Health Model for the Military. Milit Behav Health. 2013; 1:1, 41-45, p. 7. DOI:10.1080/216 35781.2012.721063

29. Dreyfus, HL Wakefield, J. From Depth Psychology to Breadth Psychology: A Phenomenological Approach. In: Hermeneutics and Psychological Theory: Interpretive Perspectives on Personality, Psychotherapy, and Psychopathology. Edited by S.B. Messer, L.A. Sass, \& R.L. Woolfolk. Piscataway, NJ: Rutgers University Press; 1988. pp 272-288. 